\title{
Reap \& Sow \\ A mind Consist of Opinions Waiting to Emerge from Rejection
}

\author{
Angela Brown \\ E-mail: brownlas6@aol.com
}

Doi:10.7575/aiac.alls.v.5n.4p.112

URL: http://dx.doi.org/10.7575/aiac.alls.v.5n.4p.112
Received: 05/06/2014

Accepted: 15/07/2014

\begin{abstract}
The American education system is a complicated form of traditional biases that restrain personal interest to pursue an equal education. Our children cannot endure the public scrutiny that is failing in educational institutions, but should be replaced with a provision of hope.

Keywords: Education, Learning power, Traditional education, Retention

We must reap and sow our education system by rediscovering invention. Children should not fear discovery. Learning is comprised of students who want to learn. Students who fail to learn, implies that we fail to educate them because of our insecurities are biased. American education can succeed if it dares to live up to its ideas that can transform the system.

We must explore the conflict in our system. Often we encounter students who are poor and disadvantaged, by creating boundaries of neglect. Boundaries often dominate interest by alienating those students from the system. We must challenge how we expose these students to learn.

Traditional practice has emerged the discourse of education reality. Social verities have created a negative image of disparity in power. A variable population have subsumed deprivation by obtaining respect. We must choose selfdiscovery over self-destruction, by having more role models cultivating fairness over a dysfunctional fear.

Education can use traditions as a tool of retention. Teachers can embody the student with familiar surroundings or something they can associate with. Education can be an informative possible alternative by influencing the landscape of cultural ideology.

Education should not distance ideas from fact. Culture is the premise of who we are. Culture is in our economy, politics and social structures. Something original is organic, while it borders our environment. These issues need to be discussed in the classroom. Students need to be introduced to these theoretic values and then tested comprehensively on the facets as the apply to the academic system.

Why do students fail? Why do students drop out of school? What can we do to provide education equality to all students? We can start by reconstructing our education system by showing students that what they learn applies to the environment they live in. Use cultural diversity as a measurement of efficacy. Explore the movement of social reform. Motivate students by engaging on what interest them.

Knowledge is a guided experience that takes preparation and time. Students will agree to learn on their own permise. By understanding how the system works relative to social conventions, will develop a framework of providing an equal education. Equality should not be a constructual restraint, but to set a pace for change.
\end{abstract}

\section{Reap \& Sow}

music salivates in passionate emotions harmoniously and in praise

a slowly hissing sound wondering here and there rolling notes of confusion escaping distance a sauntering hidden sounds of loneliness

sound mediating lost thoughts of compromise sound suspending words into open space floating notes amongst the stars wings pressed against the sky fading sound in and out of distance tongue licking the sky a saxophone murmuring cries

fading sound in and out of matter a guitar crossing thumb notes invisible sound to the universe a piano lullaby quietly plays 